Relations industrielles

Industrial Relations

\title{
Labor and American Politics, (Revised Edition), by Charles M. Rehmus, Doris B. McLaughlin and Frederic H. Nesbitt, Ann Arbor, The University of Michigan Press, 1978, 445 pp.
}

\section{Jean Boivin}

Volume 34, numéro 2, 1979

URI : https://id.erudit.org/iderudit/028975ar

DOI : https://doi.org/10.7202/028975ar

Aller au sommaire du numéro

Éditeur(s)

Département des relations industrielles de l'Université Laval

ISSN

0034-379X (imprimé)

1703-8138 (numérique)

Découvrir la revue

Citer ce compte rendu

Boivin, J. (1979). Compte rendu de [Labor and American Politics, (Revised Edition), by Charles M. Rehmus, Doris B. McLaughlin and Frederic H. Nesbitt, Ann Arbor, The University of Michigan Press, 1978, 445 pp.] Relations industrielles / Industrial Relations, 34(2), 386-386.

https://doi.org/10.7202/028975ar

Tous droits réservés @ C Département des relations industrielles de l'Université Laval, 1979
Ce document est protégé par la loi sur le droit d'auteur. L'utilisation des services d'Érudit (y compris la reproduction) est assujettie à sa politique d'utilisation que vous pouvez consulter en ligne.

https://apropos.erudit.org/fr/usagers/politique-dutilisation/ 
Labor and American Politics, (Revised Edition), by Charles M. Rehmus, Doris B. McLaughlin and Frederic H. Nesbitt, Ann Arbor, The University of Michigan Press, 1978, 445 pp.

Ce livre consiste en un recueil de textes sur l'action politique des syndicats américains. Il s'agit en fait d'une réédition modernisée du même ouvrage publié en 1967 par Rehmus et McLaughlin, deux professeurs de l'Université de Michigan. Tout comme la première édition, la version actuelle comporte deux grandes parties: l'une traitant du sujet dans une perspective historique et l'autre analysant des problèmes contemporains. C'est évidemment dans cette seconde partie que l'on retrouve le plus de nouveaux textes par rapport à l'édition originale.

Les sujets abordés dans la première partie sont les suivants: on y rencontre d'abord un chapitre d'introduction présentant une typologie des formes d'action politique syndicale et discutant d'une façon générale du rôle des syndicats comme groupes de pression dans la société. Un second chapitre rappelle les premières manifestations d'action politique des syndicats américains à l'époque des "workingmen's parties» des années 1830 à 1850. Le chapitre 3 porte sur l'action politique des Chevaliers du travail après la guerre civile alors que les chapitres 4 et 5 sont consacrés à la philosophie politique fondamentale de la Fédération américaine du travail et de son célèbre premier président, Samuel Gompers, à savoir, le volontarisme. On y aborde également des questions telles: la formation d'un parti travailliste, l'idéologie révolutionnaire symbolisée par les IWW, le parti communiste, le populisme et le socialisme. Enfin, le chapitre 6 est consacré à la réorientation de cette philosophie politique survenue à l'époque du «New Deal» des années 1930-1940.

Cette première partie comporte des articles de spécialistes très réputés en relations industrielles aux Etats-Unis tels: Adolf Sturmthal, Henry Pelling, John R. Commons, Foster Rhéa Dulles, Walter Galenson, Philip Taft et bien d'autres. L'agencement judicieux des textes permet de suivre facilement l'évolution de l'action politique des syndicats en identifiant clairement les principaux facteurs responsables de cette évolution.

La deuxième partie se veut beaucoup plus empirique. Un chapitre se consacre au fameux Comité sur l'action politique (COPE) de la FAT-COI. Il est intéressant de constater que pour un mouvement syndical officiellement neutre en politique, ou y déploie beaucoup d'énergies à surveiller de façon très étroite les positions de chaque sénateur et chaque membre du congrès américain sur les questions d'intérêt syndical. De plus, certains articles révèlent ce que plusieurs observateurs savent déjà, c'est-à-dire que le Parti démocrate a grandement besoin du support électoral de syndicats américains, surtout en ce qui concerne le choix du Président des ÉtatsUnis. La déconfiture de McGovern en 1972 en était un exemple assez frappant.

Un autre chapitre analyse la "mécanique» de «lobbying» utilisée par les syndicats lors du débat d'un projet de loi tandis que le suivant comporte une série d'analyses quant au support électoral donné par certains syndicats nationaux dans des régions ou des États particuliers.

Enfin, les deux derniers chapitres analysent les contributions financières des syndicats américains lors des élections ainsi que le comportement électoral des syndiqués. Il est intéressant d'apprendre que malgré le support officiel donné par la plupart des dirigeants des grands syndicats aux démocrates, les cotisants tentent à voter de moins en moins pour ce parti, même si une majorité d'entre eux continue toujours de l'appuyer aux élections.

Labor and American Politics est un excellent recueil de textes sur un sujet trop méconnu en relations industrielles: l'action politique des syndicats américains. Ce livre est recommandé à tous ceux qui s'intéressent au syndicalisme américain.

\section{Jean BOIVIN}

Université Laval 